\title{
ORAL MELANOMA: A FATAL ENTITY
}

Amit Pandey ${ }^{1}$, Amrita Raj², Ankita Raj ${ }^{3}$, Saket Nigam ${ }^{4}$, Shailendra S. Chauhan ${ }^{5}$

\section{HOW TO CITE THIS ARTICLE:}

Amit Pandey, Amrita Raj, Ankita Raj, Saket Nigam, Shailendra S. Chauhan. "Oral Melanoma: A Fatal Entity". Journal of Evolution of Medical and Dental Sciences 2014; Vol. 3, Issue 34, August 11; Page: 9010-9014, DOI: $10.14260 /$ jemds $/ 2014 / 3160$

INTRODUCTION: Oral melanomas are uncommon and similar to their cutaneous counterparts, are neoplasm that developed from melanocytic cells lying in the basal layer of the mucosa, its incidence is about 1.2 cases per 10 million inhabitants per year with a variation between $0.2 \%$ to $8 \%$ of all the melanomas and $0.5 \%$ of all the malignant neoplasias of the oral cavity. ${ }^{1}$

Oral conditions with increased melanin pigmentation are common; however, melanocytic hyperplasias are rare. The relative incidence amongst mucosal neoplasms of the head and neck had been reviewed by Hormia and Vuori ${ }^{2}$, about 7253 cases of malignancies of upper respiratory and gastrointestinal tracts between 1953-1964, five cases of oral melanoma were found with an incidence of $0.07 \%$.

Although, the melanocytic density has regional variation, facial skin has the greatest number of melanocytes. In oral mucosa, melanocytes 1: 10 basal cells, is seen. ${ }^{3}$ Cutaneous melanomas are etiologically linked to sun exposure, however risk factors for mucosal melanomas are unknown. They have no apparent relationship to chemical, thermal, or physical events. Intraoral melanocytic proliferations (nevi) are considered to be the potential sources of some oral melanomas. Currently, most oral melanomas are thought to arise de novo.

Pathophysiology is thought to be initiated by biochemical alteration in the precursor cells. This triggers accelerated growth and invasive potential, but not necessarily progression from horizontal to vertical growth phases. In cutaneous melanomas, well-known differences exist in the biologic behaviors of the radial growth phase-melanoma (flat or macular), vertical growth phasemelanoma (mass, nodule, elevation), and vertical growth phase-melanoma with metastasis.

Oral melanoma occurs more commonly in the Japanese, a male predilection exists with ratio being 2:1, and is seen to be diagnosed a decade earlier in males. The age ranges from 40 to 70 years, the average being 55 years ${ }^{4}$ and rare before 20years of age.5,6

The most frequent site is the hard palate followed by the maxillary gingiva, ${ }^{7,8}$ with rare sites being mandibular gingiva, buccal mucosa and floor of the mouth. ${ }^{9}$

Intraoral malignant melanomas are diagnosed clinically as pigmented lesion having irregular shape and outline. ${ }^{8}$ They remain asymptomatic and detected only when there is ulceration of the overlying epithelium and/or hemorrhage. This delayed detection may be the reason for the poor prognosis with the 5-year survival rate being between $15 \%$ to $38 \%$.6,10 Invasion of the bone may occur, increasing the likelihood of metastasis. In addition, the rich vascular supply present in the oral cavity may further contribute to the dissemination of the melanomas. ${ }^{11}$

CASE REPORT: A 30 year old female patient presented with the chief complaint of an irregular pigmented swelling in the right upper gums. The history of swelling was six months, before which, the patient had a pigmented macule which lasted for around one year. She visited a local dentist who thought it to be a mere pigmentation. It finally transformed into this swelling. 
Clinically, a large growth of $1.5 \times 2 \mathrm{~cm}$, present on right maxillary alveolar mucosa, involving the marginal, attached and interdental gingiva in relation to maxillary canine and premolars extending to the palatal mucosa. The growth was blackish brown in colour with an intact and irregular surface, firm and nontender on palpation. Hard and tender lymphnodes present bilaterally. Fine needle aspiration cytology showed some atypical melanocytes. C.T scan revealed a space occupying lesion $4.2 \times 3 \times 2.7 \mathrm{~cm}$, extending intraorally - $2 \times 1.2 \mathrm{~cm}$. Cervical lymph node status: stage T4N2M.

Histopathology showed extensively infiltrated by sheets and nests of large round to oval tumor cells with pleomorphic nuclei, prominent nucleoli, increased mitotic activity and abundant cytoplasm with brown pigment confirming the diagnosis of malignant melanoma. Immunohistochemistry showed positive results for HMB-45 and S-100 proteins.

DISCUSSION: Though these lesions are biologically aggressive, they often go unnoticed since they are clinically asymptomatic in the early stages and usually present merely as a hyperpigmented patch on the gingival surface. These lesions if diagnosed at an early in situ stage are potentially curable and definitely have a better prognosis, but unfortunately delayed diagnosis results in prognosis extremely poor. $^{12}$

Berthelsen et al identified asymptomatic swelling and occasional bleeding as the first symptoms. Only two patients $(14 \%)$ had pain. In 9 (64\%) of the oral melanomas, the tumor was located in the palate. Being painless in early stages, the diagnosis is delayed until symptoms resulting from ulceration, growth and/ or bleeding are noted as with the present case where the patient reported when the lesion was already advanced with lymph node metastasis.

The location of the lesion being present on the maxillary buccal gingiva is in accordance with the literature. Seen usually in males above 40 years, but the case presented here is of a female in her early thirties.

Cutaneous melanomas can be graded by Clark levels or the Breslow tumor thickness grading system. ${ }^{13}$

The ABCD checklist (asymmetry, border irregularities, color variegation, and diameter $>6$ $\mathrm{mm}$ ) that is commonly used to aid the identification of cutaneous melanoma may be of some utility in the clinical diagnosis of oral melanoma. ${ }^{14}$

The former classification assesses the depth of invasion, whereas Breslow's system measures the thickness of the tumor from the surface of the epidermis to the greatest depth of the tumor. The risk for developing metastatic lesions from primary cutaneous melanomas increases with tumor thickness.

The Breslow and Clark grading systems have not been validated as prognostic predictors in oral melanomas, probably owing to the rarity of this lesion. Additionally, in contrast to cutaneous melanomas, most oral melanomas were larger than $4 \mathrm{~mm}$ at the time of initial presentation. This factor, together with inadequate resection of margins and higher stage at initial diagnosis, may contribute to the discrepancy in patients' 5 -year survival rates between cutaneous melanoma (80\%) and oral melanomas (15\%).

Chaudhry et al. reported that the average duration of life from the point of diagnosis was about 18 months. Sampat and Sirsates reported that 79\% of patients died within 5 years. In addition, Vairaktaris et al. reviwed 5-year survival rate of intraoral melanoma does not exceed 5-9\%.15 
The international union against cancer (UICO) has no proposal of clinical TNM classification for malignant melanomas, but Westbury describes a clinical classification as follows: I-only primary tumor present. II-metastasis present (IIa-adjacent skin involved, IIb-regional lymphnodes involved, IIc adjacent skin and regional lymph nodes involved) and III-metastasis beyond regional lymph nodes. The patient presented here falls into the classification of IIb.

With lymph node metastasis the prognosis worsens precipitously. A 5-year survival rate in patients with positive nodes is $16.4 \%$ as opposed to $38.7 \%$ in patients with negative nodes.

According to Batsakis, 6 "there is no evidence that a preliminary biopsy of the primary lesion increases the risk of metastatic dissemination or unfavorably affects the prognosis". Any pigmented growth that may appear innocuous needs to be biopsied at the earliest.

Melanomas have a number of histopathologic mimics, including poorly differentiated carcinomas and anaplastic large-cell lymphomas. Differentiation requires the use of immunohistochemical techniques. S-100 protein and homatropine methylbromide (HMB-45) antigen positivity are characteristic of, although not specific for, melanoma. Recently, microphthalmic transcription factor, tyrosinase, and melano-A immunostains have been used to highlight melanocytes. The inclusion of these stains in a panel of stains for melanoma may be beneficial. Our case showed positive HMB-45and S-100 proteins.

Surgery is the mainstay of treatment, but often difficult because of anatomic restraints. Although melanoma is classically not very radiosensitive, patients occasionally had good response to radiation therapy, especially in early melanomas or in melanomas in situ. Other treatment modalities are similar to those used for cutaneous melanoma. Immunotherapy has been used, and chemotherapy has a low response rate. ${ }^{15}$ Though aggressive radio and chemotherapy was instilled immediately, unfortunately, the patient reported here succumbed to death within a few months after diagnosis as the lesion was highly invasive. ${ }^{1}$

CONCLUSION: Oral melanomas arise silently, with few symptoms until advanced. Most people do not inspect their oral cavity closely, and melanomas are allowed to progress until significant swelling, tooth mobility, or bleeding caused them to seek care. Pigmented lesions $1.0 \mathrm{~mm}$ to $1.0 \mathrm{~cm}$ or larger are found. Reports of previously existing pigmented lesions are common. These lesions may represent unrecognized melanomas in the radial growth phase. ${ }^{16}$

Clinicians must carefully examine the oral cavity and any growing pigmented lesion must be carefully examined and biopsied, thus avoiding a situation like here, where a local dentist just thought it to be a simple pigmentation.

Public education about self-examination of the oral cavity with periodic oral check-up is important for early detection and a routine biopsy and immunohistochemistry can help to reach a confirmed diagnosis.

Melanoma is a biologically unpredictable and deadly of all human neoplasms so, an early diagnosis and treatment, is mandatory for a better prognosis.

\section{REFERENCES:}

1. Janet 0. Guevara-Canales: Malignant melanoma of the oral cavity. Review of the literature and experience in a Peruvian Population Med Oral Patol Oral Cir Bucal. Mar 2012; 17(2): e206e211. 
2. Hormia M, Vuori E E J: Mucosal melanoma of the head and neck, J Laryngol, 83: 349-59, 1969.

3. Ebenezer: Malignant melanoma of the oral cavity. Indian J Dent Res 2006; 17:94.

4. Travis LW, Sutherland C: Coexisting lentigo of the larynx and melanoma of the oral cavity Report of a case, Oto laryngol Head Neck Surg, 88: 218-20, 1980.

5. Rapini RP, Golitz LE, Greer RO, Krekorian EA. Paulson T: Primary malignant melanoma of the oral cavity Cancer 55: 1543-51, 1985.

6. Batsakis J G: Tumors ofthehead and neck, Clinical andpathological considerations, (2'Ed.), Williams and Wilkins Co. Baltimore, pages: 431-47, 1979.

7. Shafer WG, Hine MK, Levy BM: A Textbook of Oral P Pathology, (4th Ed.) Philadelphia: WB Saunders, 133-5, 1983.

8. Regetzi JA, Scuibba JJ: Oral Pathology: Clinicalpathological correlations (2nd Ed.), Philadelphia: WB Saunders, 167-71, 1993.

9. Greene GW, Haynes JW, Dozier M, Blumbeg JM, Bemier JL: Primary malignant melanoma of the oral mucoua Oral Sorg Oral Med Oral Pathol, 6:1435-43.

10. Green TL, Greenspan D, Hansen LS: Oral melanoma report of a case. J Am Dent Assoc, 113:6279, 1986.

11. Eisen D, Voorhees IT: Oral melanoma and other pigmented lesions of the oral cavity, J Am Acad Dermatol, 24:527-37, 1991.

12. Padhye A, D’souza J: Oral malignant melanoma: A silent killer? J Indian Soc Periodontol. 2011 Oct-Dec; 15 (4): 425-428.

13. Snow GB, van der Waal I. Mucosal melanomas of the head and neck. Otolaryngol Clin North Am. 1986; 19: 537-547.

14. Rogério 0. Gondak: Oral pigmented lesions: Clinicopathologic features and review of the literature. Med Oral Patol Oral Cir Bucal. Nov 2012; 17 (6): e919-e924.

15. Hashemi Pour M S: Malignant melanoma of the oral cavity: A review of literature. Indian J Dent Res 2008; 19: 47-51.

16. Bobby McManus Collins II: Overview: Oral malignant melanomas; Updated: Feb 11, 2013.

Fig.1: Showing infiltrated by sheets and nests of large round to oval tumor cells with pleomorphic nuclei, abundant cytoplasm with brown pigment confirming the diagnosis of malignant melanoma.
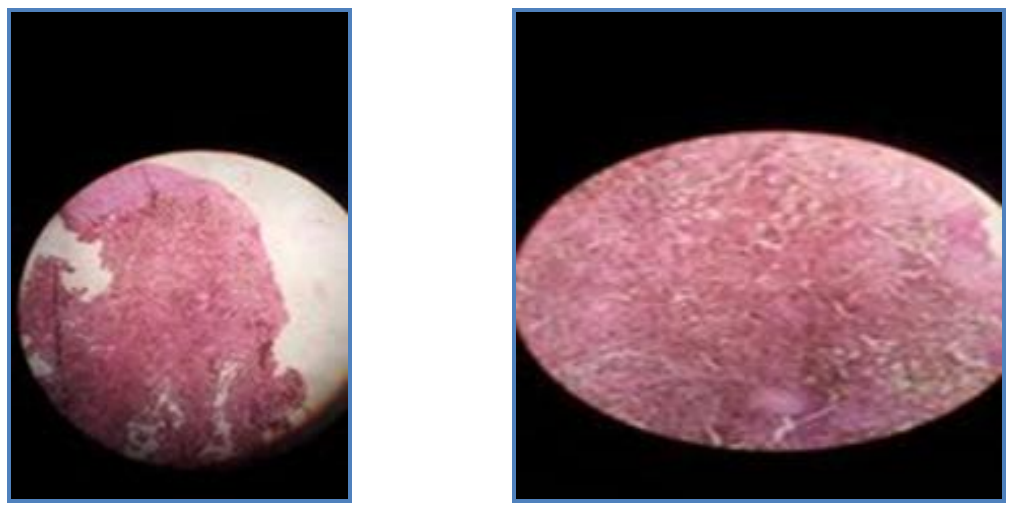

Fig. 1: H \& E Stain 


\section{CASE REPORT}

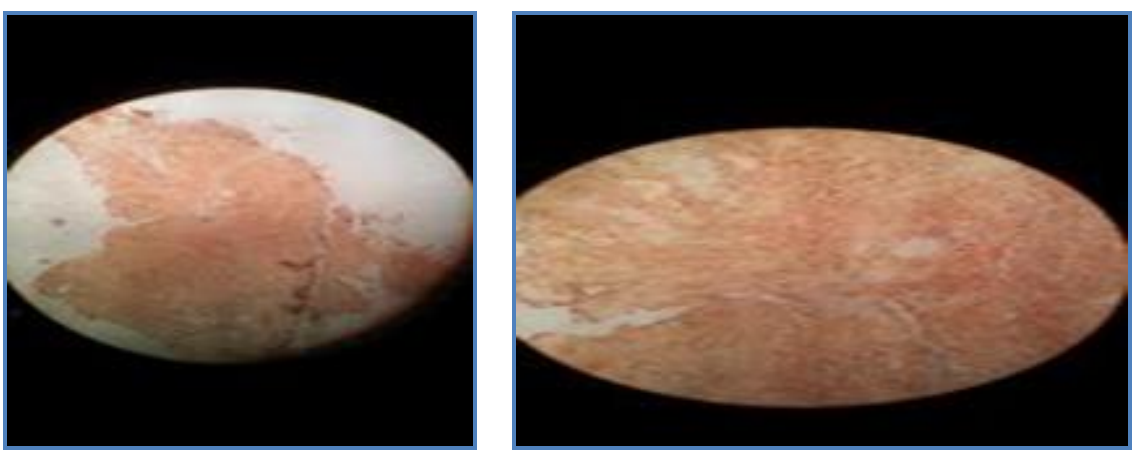

Fig. 2: Showing S-100 positive
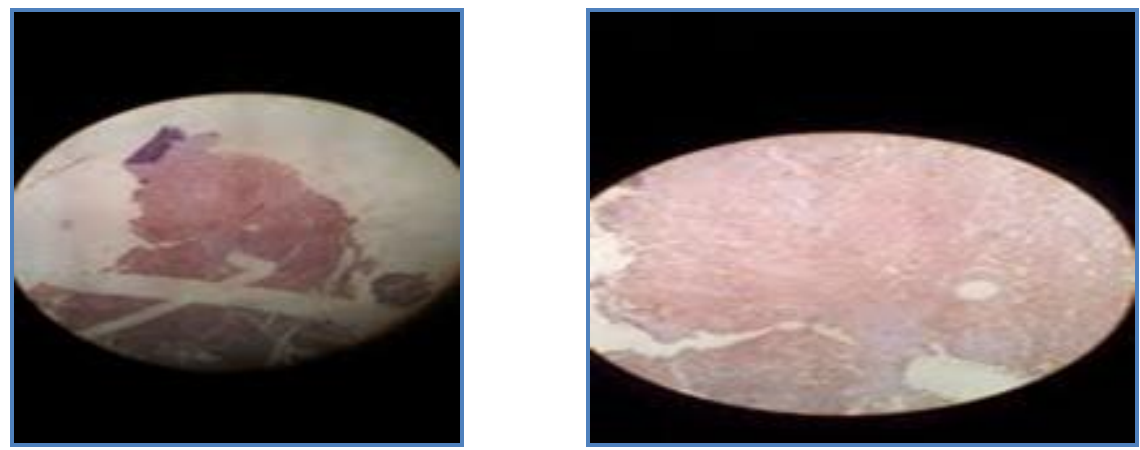

Fig. 3: Showing HMB-45 positive

\section{AUTHORS:}

1. Amit Pandey

2. Amrita Raj

3. Ankita Raj

4. Saket Nigam

5. Shailendra S. Chauhan

\section{PARTICULARS OF CONTRIBUTORS:}

1. Senior Lecturer, Department of Periodontics, Rama Dental College, Kanpur.

2. Senior Lecturer, Department of Oral Pathology, Rama Dental College, Kanpur.

3. Senior Lecturer, Department of Oral Surgery, Rama Dental College, Kanpur.

4. Assistant Professor, Department of Radiology, Rama Medical College, Kanpur.
5. Senior Lecturer, Department of Periodontics, Rama Dental College, Kanpur.

\section{NAME ADDRESS EMAIL ID OF THE CORRESPONDING AUTHOR:}

Dr. Amit Pandey, \#617, Lakhanpur, Kanpur.

Email: dramitpandeydental@gmail.com

Date of Submission: 15/07/2014.

Date of Peer Review: 16/07/2014.

Date of Acceptance: 02/08/2014.

Date of Publishing: 09/08/2014. 